\title{
Economic theory and (ontological) reductionism: some pitfalls on the road of the microfoundations project ${ }^{*}$
}

\author{
Celso Neris Jr ${ }^{\dagger}$ \\ José Ricardo Fucidji
}

\begin{abstract}
This paper approaches the literature related to the microfoundations of the macroeconomics project. Its contribution lies in analyzing the ingrained reductionism in the project and its unsuitability both in its own terms and in the purpose of understanding better socioeconomic reality. We also claim that, in addition to a project of science (the sound or rigorous way of doing 'scientific' Economics), it includes an implicit ontology of market sociability that establishes links between microfoundations and the neoliberal ideology. Attempts such as complexity theory and old institutionalism to overcome the reductionist individualism of microfoundations are also evaluated and pointed out both their potentials and their shortcomings. In order to deal with a complex hierarchically multi-level structured and open reality the Economic Theory should avoid explanations that conflate reality to a single level. It should instead prefer approaches in which micro and macro levels are mutually conditioned and relatively autonomous.
\end{abstract}

Keywords: Economic methodology; Reductionism; Microfoundations.

JEL classification: B41; A14; B1

\footnotetext{
** $O$ autor agradece aos comentários de Carmem Feijó e dos pareceristas anônimos. Uma versão preliminar foi apresentada no XII Encontro Internacional da AKB. Este trabalho teve apoio financeiro da CAPES (Coordenação de Aperfeiçoamento de Pessoal de Ensino Superior).

+ Professor substituto no Departamento de Economia da Universidade Estadual Paulista (UNESP) e pesquisador de pós-doutorado do Programa de Pós-Graduação em Economia da UNESP. E-mail: cnerisjr@gmail.com

‡Professor no Departamento de Economia da Universidade Estadual de Campinas (UNICAMP). Email: fucidji@gmail.com
} 


\section{Introduction}

There is an extensive literature on the microfoundations of macroeconomics which is of a wider interest than that curbed to the academic debate as it influences how macro policies are construed and with which persuasion strategies they are prescribed to governments and to public opinions. Keynes would say that we are ruled by defunct economists. It is true but not the whole truth. We are ruled by living economists who reinterpret Smith's, Ricardo's, Walras', Marshall's or even Keynes' thoughts in a specific way. This paper highlights the effects that interpreting (accounting or molding) the economy has on the economic policy. Thus, this paper inquires what are the methodological (i.e., in what forms theory must be formulated) and ontological (i.e., what it assumes, even implicitly, about the entities of social reality) implications of the microfoundations project.

For our ontological analysis of the microfoundations project of Modern Macroeconomics ${ }^{1}$ we chose a philosophical ontology (i.e., the study of the relationship between theoretical entities and their referents in the external world) rather than a scientific one (i.e., the study of theoretical entities within theories which we happen to be interested in) - such distinction was made amongst others by Lawson (2014, pp. 22-28). We do not mean that scientific ontology (or "internal metaphysics") analysis is of lower importance or value. Even though there are plenty of good scientific ontology analyses, particularly the Uskali Mäki's contributions, though they do not focus a lot on critique. Moreover, evaluating the microfoundations project by its internal metaphysics (the role played by representative, hyper-rational agents in the theoretical schemata) would lead us to an account of its internal logic and, as insightful as it may be, it would halt there.

After surveying some problems of the microfoundations project we related them to its implicit reductionist ontology by using philosophical ontology as developed by the critical realism for its insistence on the issue of the matching between methods of analysis and subject matter. Following this lead and Soromenho's (2000) argument, we present the ontology of the microfoundations project as the sociability of independent producers (a simple mercantile society where property asymmetries and capital accumulation are absent) in which the only

\footnotetext{
${ }^{1}$ By "Modern Macroeconomics" we mean the dominant theory until at least the financial crisis of 2007-2008. It can be identified by the requirements that theories must be microfounded, namely, agents with substantive (or hyper-) rationality and rational expectations; dynamic stochastic general equilibrium (DSGE) models; and macro policies that assume non-neutrality of money in the short run. This theory is associated with the new Keynesian, the new Classical and the new Neoclassical Synthesis schools (Goodfriend and King, 1997). Moreover, our definition is close to Colander et al. (2004) about theoretical dominance in the academic community. Thus, "modern macroeconomics" and "mainstream" are here interchangeably used.
} 
social link is the contingent act of exchange. This ontological conception is suitable to the project in two ways: on one hand, it maintains the agents' autonomy (deemed as atoms in their relations to one another) and, on the other, assuming that the agents' behavior is strictly self-interested and hyper-rational, it draws implications to the systemic level by searching for coordination mechanisms to make the individual plans mutually compatible.

So, although this project complies with the methodological individualism desideratum its ontological implications forcefully misrepresent what we know about real world agents. In other words, the agents' behavior as required in the model is heroic or implausible when related to real decision makers. Moreover, essential features of agents such as the very possibility of free choice and their environments (the supra-individual conditions) are explained away in order to facilitate the project coherence with the postulates of free and perfect markets that would seem awkward to Smith, Ricardo and even to Walras maybe.

In Section 2, we discuss the problems of the microfounded economics project its ontological implications and consequences. The Section 3 of this study deals with some alternatives pointing out theories that are both more contextual and more empirically robust. Social institutions, for instance, are particularly picked out as productive analytical units for studying socioeconomic phenomena according to a realist ontology. At last, Section 4 brings in some final comments stressing some of the risks of a proposed alternative (complexity economics) sliding back into reductionism.

\section{Reductionism in the modern macroeconomics}

Reductionism is a proposition according to which a whole must be completely explained in terms of its components. In a broad sense reductionism can be defined as the conception in which all the features of a complex phenomenon must be fully explained in terms of a single level or kind of entities. In this section, we shall see how reductionism is associated with three aspects of the Modern Macroeconomics, namely, (i) its scientific project; (ii) the reinforcement it lends to a certain market sociability view; and (iii) its leanings to the neoliberal ideology². We

\footnotetext{
2 By "neoliberal ideology" we mean a market-oriented view of the policymaking or free-market economics as does Backhouse (2010, p. 149): "Phenomena that economists outside the [Chicago] tradition might have seen as demonstrating market failure or irrationality were examined until they were reconciled with this presupposition. This can be defended as a methodological position relating to what constituted rigorous economics, but it was a methodological position centered on a view of the world, namely a presupposition, or prior belief, that markets were efficient unless proved otherwise. Theory was, de facto, grounded on an ideological position". That is also what Denis (2004) calls laissez-faire.
} 
also remark briefly on the unfeasibility of reductionism in the presence of emergent phenomena.

\subsection{Modern macroeconomics as a scientific project}

"Reduction" is commonly understood as to make it smaller, to decrease it in number or size. In the philosophy of science, it means to decompose a complex entity or to make it simpler in order to reach its more basic components. There is a long tradition in Western thought where it is used metaphorically referring to "bridge laws" that connect theories from different domains (e.g., micro and macroeconomics). John King, for that matter, adopts the following definition given by the philosopher of science Kenneth Schaffner: "Intertheoretic explanation, in which one theory is explained by another theory, usually formulated for a different domain, is generally termed theory reduction" (Schaffner, 1967, p. 137; author's italics). Just after this quote King asserts that the microfoundations project (he calls it "dogma") is a special case of that general principle (King, 2012, p. 27). Prado, in turn, affirms that reductionism implies dividing more complex objects into its small component parts and so explaining them conveniently, that is, the explanation should "begin from simpler and easier to know objects, ascending, as if in a stairway, step by step to the knowledge of composites" (Prado, 2006, p. 13).

According to Hodgson (2000, p. 110), the biological reductionism was used in the social sciences as a form of explanation in the 1870-1920 period. In biological reductionism, individuals and groups behaviors are explained in terms of their biological characteristics. However, In the 1920s, biological reductionism was broadly abandoned by them, having a revival later with Sociobiology in the 1970s. But, in Economics, things were slightly different not only because marginalist theories were mechanicist, as Hodgson also notes - and so not biology-inspired, but also because Macroeconomics enjoyed a relative autonomy between the decades of 1930 and 1960. At the end of the twentieth century, methodological individualism ${ }^{3}$ was the main type of reductionism used in social sciences in general and in Economics in particular.

In Economics, microfoundations - explaining macroeconomic phenomena completely in terms of entities from the microeconomic domain containing especially optimizing agents with rational expectations - is a particular case of reductionism. Ganem (1996, p. 113; italics added) says that microfoundations of

\footnotetext{
${ }^{3}$ Udéhn (2002, p. 497) defines methodological individualism as "a principle, rule or programme telling historians and social scientists how to define collective concepts, explain social phenomena, and/or reduce macro to micro". And Janssen $(2008$, p. 600$)$ explains that "the quest for microfoundations grew out of the widely felt, but rarely explicitly stated, desire to stick to the position of methodological individualism".
} 
Modern Macroeconomics is a project that aims to identify "the collective laws that would reflect the individual maximizing behaviors" and that "this research field ended up imposing itself as the only rigorous (scientific) project". In the same vein, Hoffman and Pelaez (2011, p. 266; authors' italics) state that "the idea according to which the scientific approach must be necessarily based on any kind of (rational) individualism should be questioned". The idea of necessity, we add, implies that there is no room for alternative macroeconomic theories beyond the one with a particular interpretation of the microeconomic domain. That is why we claim that microfoundations reductionism is a scientific project.

This project traces back to the old physicalistic dream of the logical positivism of the Vienna Circle. According to O'Neill (2004, p. 436) physicalism was a unification project of the sciences that could take many forms: "(i) a reductionist project in which all sciences would be logically derivable via bridge-laws from physics; (ii) a programme for a unified method which would be followed by all sciences; (iii) a project for a unified language of science; and (iv) a project that would integrate the different sciences such that on any specific problem all relevant sciences could be called upon - a project for the 'orchestration of the sciences'". That ambition, although discredited and never accomplished, was influential in the twentieth century scientific imagination deeply affecting the way of conceiving and doing science. It survived, via Popper, in the requirement that the social sciences must be based on the principle of individual rationality and, pour cause, on methodological individualism (Caldwell, 1991, p. 16; Hodgson, 2007, p. 212).

To Elster (1983), methodological individualism is a doctrine according to which all social phenomena (its structure and change) are to be explained exclusively from individual properties, aims and beliefs. Such individual assumptions are useful to a project of science:

[t] he basic building block in the social sciences, the elementary unit of explanation, is the individual action guided by some intention... Generally speaking, the scientific practice is to seek an explanation at a lower level than the explandum... The search for microfoundations, to use a fashionable term from recent controversies in economics, is in reality a pervasive and omnipresent feature of science (Elster, 1983, pp. 20-24, author's italics).

The rise of the neoclassical economics after the 1870s consolidated reductionism in Economics by bringing forth an analytical framework in which individual choice given by utility functions under constraints was the gist of the theoretical explanation. On this principle, individualism, reductionism and atomism were gradually intermeshed throughout the twentieth century. Hodgson argues that problems of choice under constraints became the dominant topic, and it 
strengthened preferences/utility optimizing as a feature of utmost importance in Economics. Hence, individuals are seen as social atoms:

In the social sphere the human individual was seen as the fundamental unit of analysis: the indivisible particle in motion. Of course it is accepted that individuals, like particles, are affected by their circumstances in the manner of the forces and constraints that impinge upon them. But in such an atomist social ontology the essential aspects of human personality and motivation are conceived as independent of the social relations with others. (Hodgson, 1993, p. 70).

The atomist ontology is dovetailed with the reductionist methodology. In the microfoundation project theories from different domains are unified by the requirement that macro phenomena must be reducible to micro level phenomena. Its corollary is an explicit epistemological monism in which there is only one scientific way of interpreting and theorizing the economic reality ${ }^{4}$. A correlated issue is that the search for microfoundations strengthens a specific conception of sociability based on individual rationality and spontaneous order.

\subsection{Strengthening a market-oriented conception of sociability}

Modern Macroeconomics is built on the ontological assumption that "individual components of the analytical architecture must be entities closed in themselves and externally related one to another" (Prado, 2006, p. 307). The key features of the represented entities in the macroeconomic models as well as their internal relations with other entities were gradually erased on behalf of the axiomatic deduction of the individual's optimizing behavior. The possibility of the individual behavior being oriented by supra-individual institutions as well as idiosyncratic behaviors is therefore denied. That is to say that these models assume that individuals are prevented from determinations coming from the social structures they live in and also that their internal structure is invariable so as to facilitate homology between (or conflation of) ontologically different domains.

This poor account of the individual in methodological individualism in Economics as well as in other social sciences carries an intractable analytical problem: either one cannot justify reduction (Why to rest in the individual and not in its psychological or biological determinations?) or it is unfeasible to fully reduce entities to their indivisible components (Hodgson, 2000, p. 111; Udéhn, 2001, pp. 323-324).

Now, what is the microfoundations project implicit sociability? By sociability, we mean the kind of interaction amongst individuals that is assumed in theoretical

\footnotetext{
${ }^{4}$ The term "epistemological monism" is not used here in the traditional sense of a unified science over natural and social domains but as a way of making sense of the macroeconomic phenomena albeit there are more than one reductionist methodology. We thank a referee for drawing our attention to this point.
} 
contributions to this project. Soromenho (2000) drawing upon Persio Arida's early papers gives us an account of the market sociability implicit in the general equilibrium theory. On our turn, we have taken Soromenho's account for it can be equally applied to the microfoundations project. Soromenho says that this conception of sociability was originally proposed by classical economists (a stylized commercial society populated by independent producers bonded by market exchange) and later resumed by neoclassical ones in a thread that went from Hicks to Samuelson to Arrow and Debreu. In this idealized conception of society, exchange is the only social bond amongst commodities owners. In the last century, the task authors have assigned to themselves was to erase from mercantile order explanations any mention to supra-individual determinants. Individuals with their preferences, initial endowments and technologies were conceived as the only determinants of social outcomes. Therefore, it is all about explaining market workings based exclusively upon individual attributes. Two issues are regarded within that theoretical framework as scientific relevant: if the agents plans are mutually compatible (whether there is spontaneous order in the market process) and how coordination of such plans is obtained (or how equilibrium is reached). Those are the well-known themes of existence, uniqueness, and stability of the general equilibrium theory (Soromenho, 2000, p. 203 onwards).

It would be beside the point harking back to the research problems in the neoWalrasian General Equilibrium Theory. Suffice it to say that although regarded as the standard of academic quality and rigor, the assumption according to which the agent level is enough to bring about order at system level is far from having "sound foundations" in its own axiomatic terms. As Soromenho shows, existence of equilibrium can be demonstrated, but there are no obstacles to multiple equilibria. In the latter case, the problem of uniqueness is added to the stability problem: in order to choose amongst a few of possible equilibria one must know the economic system past trajectory and thus its dynamic features which are, by definition, out of equilibrium. However, notions such as rationality and mechanisms (if any) to converge towards equilibrium have much vaguer meaning out of equilibrium.

Albeit respectful of the conventional approach, Soromenho (2000, pp. 208209) points out that in order to get robust results of stability one needs to resort to supra-individual entities (the "well-organized" markets and "auctioneer" assumptions as in Hahn and Neghishi's 1962 model; see Janssen, 1991) and strongly constrain the individual rationality assumption (static expectations of future prices). There is no better testimony to the limitations of the general equilibrium hypothesis on 
individual substantive rationality and spontaneous market order - and also about the alternative path one should follow.

We must distinguish at this point methodological from ontological individualism (Hodgson, 2007, pp. 214-215). According to methodological individualism social phenomena must be explained in terms of individual entities, but that implies nothing about the existence of other entities. However, the microfoundations project also implies an ontological individualism, namely, reality is composed of individuals and their contingent relations ${ }^{5}$ to one another. If that is the case, then the microfoundations project implies a normative feature: economic agents must be taken into account through the notion of (idealized) relations as wealth owners who are guided only by their self-interest. As we shall see later this feature makes an association between the microfoundations of Macroeconomics and the neoliberal ideology.

We argue that there are at least three implications stemming from this ontological individualism. Firstly, stating that foundations (building blocks) must come first is a constitutive metaphor that thoughtlessly assumes a distorted conception of theorizing in Economics opposed to its historical development and excluding alternative approaches. To establish this concept as the only right or scientific way of doing Economics is detrimental to the development of Economics as a science, to say the least. Moreover, the reductionist ontology of optimizing individuals has been exported to scientific endeavors outside Economics. Freakonomics, for example, is a best-selling book that applies the rational choice principles to problems investigated in other social sciences (for a critical evaluation see Fine and Milonakis, 2009, Chapter 6).

Secondly, since the microfoundations methodology is regarded as the only rigorous way of theorizing in Economics it grants academic advantages for those do, over economists that for any reason do not, use it - "competitive advantages" in the market of ideas, in publishing in most prestigious journals, in getting their research funded and so on. Notwithstanding the fact that its success in terms of sociology of science is far beyond its actual achievements except it if "rigor and elegance" are the only criteria to evaluate theoretical work. In this case, scientific advance is regarded

5 Otherwise, if the relationship among entities is necessary (internal) then methodological individualism is impossible as recognized even by Hayek (1967, pp. 70-71): "The overall order of actions in a group is in two respects more than the totality of regularities observable in the actions of the individuals and cannot be wholly reduced to them. It is so not only in the trivial sense in which the whole is more than the mere sum of its parts but presupposes also that these elements are related to each other in a particular manner. It is more also because the existence of those relations, which are essential for the existence of the whole, cannot be accounted for wholly by the interaction of the parts but only by their interaction with an outside world, external both to the individual parts and the whole". 
as a semantically and internally defined concept. Rigor and elegance should not overcome the external criteria of relevance and capacity to enlighten the social reality ${ }^{6}$. It is no wonder that, in spite of the internal consistency problems pointed out in his paper, Soromenho (2000, p. 214) gives a sociology of science argument for the persistence of the general equilibrium theory as a benchmark of theorizing: it allows "wielding a set of (formal) techniques... in whose conversation other approaches engage in".

Thirdly, the microfoundations project is an attempt of suppressing the macro domain thus denying autonomy of subject-matter to macroeconomics, except for differences in level of aggregation and aims of the task at hand. In the well-known phrasing by Robert Lucas the terms "macro" and "micro" should eventually disappear:

most interesting recent developments in macroeconomic theory seem to me to be describable as the reincorporation of aggregative problems such as inflation and the business cycle within the general framework of 'microeconomic' theory. If these developments succeed, the term 'macroeconomic' will simply disappear from use and the modifier micro will become superfluous. We will simply speak, as did Smith, Ricardo, Marshall and Walras, of economic theory. (Lucas, 1987, p. 108).

In other quarters, continuing efforts are being made by economists to enlarge what we know about individual behavior (often resorting to other sciences) and its relationship to its multiple, fuzzy, changing contexts. Here we think of recent developments in behavioral, experimental and neuroeconomics as well as approaches under the umbrella of complexity economics (Davis, 2008). This line of inquiry allows that micro and macroeconomy are distinct, though related, domains of the economic reality. Contrary to or in spite of these efforts Modern Macroeconomics has resisted to changing its axioms about individual behavior. We claim that this resistance to change its mode of explanation accounts for the kinship between Modern Macroeconomics and the neoliberal ideology. Let us turn to this point.

\subsection{Affinity between modern macroeconomics and neoliberal ideology}

Denis (2004) in his paper on two rhetorical strategies of laissez-faire (namely, reductionist and holistic) states that in Modernity individual self-interest should be

\footnotetext{
${ }^{6}$ Here we part ways with Soromenho. If our interpretation is right, he subscribes to the semantic view of theories according to which theories should not be evaluated by their correspondence to entities in the external reality (since no theory can fully attend to that requirement) but by their ability "to conciliate theory with facts [interpreted according to this same theory]" (Soromenho, 2000, pp. 197 198). Elements of our dissent involve broader issues of self-referentiality, abstraction and idealization. Suffice it to say that allowing that all theories are unavoidably unrealistic, for all of them involve abstraction and idealization, it does not follow that different procedures of abstracting and idealizing (classical, neoclassical, marxist, neo-Walrasian and so forth) should be regarded as equals from a methodological viewpoint (see Mäki, 2006, and Lawson, 1997, Chapter 16).
} 
articulated to the general interest in order to be legitimated. That is to say that individual plans or aims should match or at least be congruent to collective ones. Two rhetorical strategies were thus used to account for this articulation or, in our terms, to build the relationship between the micro and the macro level.

Drawing upon Denis (2004) we shall limit ourselves to the reductionist strategy. In his account of reductionist persuasion strategies throughout the Economic Thought History Denis delves into some nineteenth and twentieth centuries economists, among whom we are only interested in Lucas and his conception of economic society. Lucas subscribes to Friedman's statement that economics is the study of "a number of independent households, a collection of Robinson Crusoes" (Friedman, 1962, p. 13), when he says that "an economic system is a collection of people" (Lucas, 1987, p. 29).

This phrasing implies by allusions to number and quantity that individuals are regarded as isolated entities relating to one another in a contingent, external way (i.e., individuals are social atoms). Thus, we can note that the microfoundations project openly creates (or produces or builds`) similarities of individual entities such as households and governments. This analogy often shows up in public debate on austerity policies as a powerful rhetorical resource in as much as it equates (and so are the lay people taught) decreases in government deficits with a household struggling with its own budget. Now, by drawing upon this simple analogy between two very different (macro and micro) domains Modern Macroeconomics is rhetorically more prone to influence the public imagination.

An example of the ideological bias of Modern Macroeconomics is given by Denis (2004, p. 344) when he discusses unemployment as a social disease. One could, he says, adopt at least two approaches: either (i) unemployment is an emergent phenomenon at the macro level and is therefore unintentional or (ii) it is the aggregate or sum of all individual decisions at the micro level. Lucas unmistakably and emphatically adopts the second approach. According to Lucas (1987, p. 54), to explain why an agent allocates her time to an activity (leisure, i.e., the decision of being jobless) is to know her reasons to prefer this to all other available activities. As Denis (2004, pp. 344-345) states, Lucas' aim is clear: if unemployment is the mere summation of individual decisions of staying jobless then it is possible to demonstrate that neo-keynesian policy activism is misconceived.

\footnotetext{
${ }^{7}$ Considerations of space hinder us from discussing the performativity thesis in Economics (see Boldyrev and Svetlova, 2016). For a critical stand see Fucidji, Almeida and Neris Jr. (2016).
} 
Lucas' rhetorical strategy is reductionist. He asserts that one needs to solve separately the problem of "understanding laborers' individual behavior" and then explain the reason why they prefer, as an aggregate, other activities rather than work (Lucas, 1987, p. 68). Unemployment is regarded simply as an individual choice, a private problem. If employment is freely decided in a work-leisure trade-off then there is no social disease, and a government intervention is not needed. It is no wonder that new classical economics is famous for its propositions regarding the many kinds of macro policy inefficacy. Arguing for capitalism without government intervention is a neoliberal feature common to Friedman's and Lucas' ideological stands - and, more generally, to the Chicago School.

New classical propositions on unemployment as well as on policy inefficacy were loosened by the new Keynesians. However, they have taken the reductionist bent of new classicals by adopting the methodological proposition that macro must be explained by the microfoundations of optimizing individual behavior. Even though arguing for government intervention their recommendations are always shy as can be seen in the literature on the independence of central banks. Only lately has expansionary fiscal policy been taken into account by modern macroeconomists albeit without dispensing with the microfoundations requirement. That is why we claim a bond between Modern Macroeconomics and laissez-faire policies. In the same vein, the proposition of stabilization policies detrimental to economic growth (despite all its technical apparatus and jargon) is also a kinship to the neoliberal mindset. In this way, the microfoundations project is not just epistemologically monist and ontologically reductionist it also strengthens, and it is supported by an ideology that accounts for its resistance to change.

\subsection{Shortcomings of reductionism in economics}

There is another way of regarding economic reality. If reality, including the economy, is multi-leveled - where complex, emergent and changing phenomena take place then the reductionism of the microfoundations project is fatally unfeasible. Here we make some brief observations on the obstacles that a realist conception of the economy presents to reductionism in Economics.

A system is regarded as complex when the interaction among its components changes the overall system behavior, that is, new dynamics are created defying a general statement of its workings. Certain analytical solutions for those systems are possible but only if simplifying assumptions are taken which falsify the real complexity of the subject (Hodgson, 1993, p. 75). An apt characterization - as there are dozens of definitions - is given by the advertisement for the collection Complexity in Economics (Rosser Jr., 2004): 
Complex dynamics in economics arise from nonlinear systems that do not converge to a fixed point, a limit cycle, or explode or implode exponentially due to endogenous factors. They arise from cybernetics, catastrophe theory, chaos theory, or the varieties of modern complexity theory, including models with heterogeneous, interacting agents.

An example of complexity is the chaos theory. It shows that tiny variations in the initial conditions can cause huge changes in the results. It is therefore impossible to forecast the workings of the system by studying its components - either for precision of the initial conditions is poor or because one cannot warrant a good description of interaction and feedback mechanisms operating among the components or between them and the outcoming system. Another example are simulation models of heterogeneous agents. Those models are able to display the workings of simulated theories but are for that very reason unsuitable to a general, unified formulation ${ }^{8}$ (Squazzoni, 2010, p. 221). Hodgson (1993, pp. 79-80) states that models with chaotic dynamics can produce order (and vice versa ordered models can produce chaos) since there is enough structural stability (defined as the ability to dissipate feedbacks and heterogeneity effects at the components level) in the system. Kirman (2016) is more skeptical about the possibility of complex dynamics being guided by attractors. According to him, such attractors are also liable to evolution and it makes policymaking based on models even harder (Kirman, 2016, p. 536).

That brings us to the point of emergence. As well as complexity there are many definitions of this concept (see Sawyer, 2001). Gilbert (2002), for example, uses "emergence" and "result" almost as synonymous. Still, for our purposes it is interesting to take the ontological definition of emergence as given by Hodgson (1993, pp. 78-79): an entity or phenomenon is emergent if it is formed by components at a lower level of reality, but it is not reducible to these lower-level components. A good example is given by the biologist Ernst Mayr (1985, p. 44): "every biologist would insist that to dissect complex biological systems into elementary particles would be by all odds the worst way to study nature". In the act of ontological reduction properties or features of higher-level entities are lost. It follows that reality should be studied as a "structured hierarchy" where each level has relative autonomy functioning by its own mechanisms and architectures and engendering emergence non-predictable from analyses of its components. An ontology of emergent entities is in accord, for example, with post Keynesian macroeconomics that have always criticized fallacies of composition in Macroeconomics. As stressed by Hodgson (1993, pp. 80-81) the analytical aim is to

\footnotetext{
${ }^{8}$ And it may be better this way. Models that are more sensible to specific factors - and because of that can embrace historical and geographical specificities, overall are more useful than those that patently contravene the reality they should account for - for the sake of tractability or generality.
} 
elucidate the workings and interactions amongst components at a given level as well as the interaction amongst levels.

Finally, there are plenty of good reasons to incorporate evolution as a phenomenon of the ontology of the economic reality. In the Modern Macroeconomics the homogeneous, representative agent is made by fiat (it is a solicitor of its micro clones) and the agent is unable to take non-optimizing actions since it is assumed that it knows the model that best describes the workings of the economy. Ironically, free choice, so dearly regarded by laissez-faire ideology, is falsified by that. As Lawson (1997, p. 30) points out: in models that deal with substantive rationality and "single exit" solutions, there is no real choice. Choice is only free when an agent, facing a situation $\mathrm{S}$ where the best choice supposedly is $\mathrm{x}$, can choose $x$ or $y$ or other totally different (innovative) choice. One should note that there are many accounts for non-optimizing behavior that do not imply "irrationality", from the uncertainty about the other's behavior to the Schumpeterian drive to break the routine. Moreover, complex and emergent and innovation phenomena are related and as a block are incompatible with the reductionist microfoundations project. Economic systems display complex and unpredictable (i.e., open) paths in that conception of ontology. Economists must pay more attention to partial, local and lower-level regularities and investigate their interactions in order to suggest some hypotheses about aggregate outcomes. Fear of this indetermination (an ontological feature) and our poor control over the system may be the (unspoken) rationale for the noted strong attachment to the deterministic models of modern macroeconomics.

\section{Insufficiency of formalism as a solution to reductionism}

The mathematical formalization, as privileged means of interpreting and intervening in the economic reality, is a key methodological feature of the mainstream Economics. Formal modeling is regarded as a higher ability of theorizing and as a border line to distinguish Economics from other (more "literary") social sciences. As said earlier, in the mainstream models' assumptions about individual behavior and systemic equilibrium they are adopted for tractability and/or generality reasons in blatant opposition to a realist ontology of Economics as a social theory ${ }^{9}$.

\footnotetext{
${ }^{9}$ Social reality (or domain) is understood here according to critical realism. Critical realists assume that there is an objective reality external to the scientific effort, that is to say, entities exist objectively and independently of the theoretical constructs of scientists. Social reality is conceived as open and structured, composed by three strata: empirical (where events or states are perceived by our senses); actual (events or states themselves) and real or deep (mechanisms underlying and producing items in the actual stratum). In fact, at each level or reality domain (social, psychological, biological, chemical, physical, and so on) these strata are operative (See Lawson, 1997, pp. 15-65, for details).
} 
The Economic Theory has rested far too long on three fundamental assumptions: self-interest, rationality, and equilibrium (Colander et al., 2004, p. 485). In fact, provided with those assumptions it does not matter for the mainstream whether an American and a Pakistani, for instance, have distinct behaviors. They are reduced for theoretical purposes to a single behavior. It is no wonder that international organizations or influential economists prescribe policies almost identical to countries structurally very different. The prestige network created by the positions in government agencies, international organizations and rating agencies promotes more and more adherence and allegiance to the mainstream, in scholarship as well as in society (here we are in accordance with the performativity thesis, see footnote 5). If in periods of economic crises, one believes that this state of affairs must change - due to evident discomforting anomalies - that net of influences in the economic system rescues most of the mainstream at least for a while. For example, after recent changes in the cutting-edge Economics the scene in policymaking remains the same or "the more things change, more they stay the same" (Palley, 2013, pp. 193, 203, 205).

Colander et al. (2004) tend to be more optimistic. They suggest that what happens in the cutting-edge Economics changes the mainstream influencing the future developments of the profession of the area. Cutting-edge is a notion that includes even some works by critics of the mainstream which implies that the mainstream contents are often being challenged to be updated, modified, and expanded. Diversity of visions within the mainstream predicts future changes in the Economics:

[T] he reality is more complicated; conventional economists often hold a variety of views simultaneously. If the variance of views increases, while the core remains relatively unchanged, the static characterization of the profession will not change, but its dynamic characterization will. (Colander et al., 2004, p. 487).

Recently in studies which discuss the role of Economics and economic methodology in the financial crisis of 2007-8 (Colander et al., 2009; Colander, 2010; 2013) they were less optimistic about change. They argue that economists should not be blamed for their inability to predict the crisis because crises, in general, are of course unpredictable events. However, they should be criticized for their excessive reliance on certain models (i.e., DSGE) that allow only one kind of microfoundations and disregard the complexity of the real world (Colander, 2010, p. 419). Moreover, economists were unable (or unwilling?) to communicate to the public the serious limitations and lacking qualifications of the models they were using. The authors suggest that formal models should be improved, turning Economics into Complexity Economics. We shall return to this point. Now, one should note that albeit most of 
the critiques of formalism are not new it is so deep-seated in the Economics that it even jeopardizes the Complexity Economics alternative.

\subsection{The crumbling of the microfoundations project}

From the survey of problems faced by the general equilibrium theory (Section 2.2 of this work) it is fair to say that according to its own practitioners (pace modern macroeconomists) the scientific programme of drawing macro results exclusively from micro standardized behavior has failed. Summing up, Rizvi (1994, p. 363) states that Sonneschein, Mantel and Debreu findings show that the assumption of individual rationality does not provide guidance to macroeconomic analysis for it is insufficient to bring about the desired systemic regularities.

Hodgson (2000, p. 107) adds that because of the arbitrariness and stability problems in the general equilibrium research programme one can conclude that an economy populated by atomistic agents does not have sufficient structure to survive for its states of equilibrium could be evanescent. Attachment to the microfoundations project thus involves a leap of faith into the "invisible hand" and into the agents' calculative abilities. This theoretical effort, Hodgson continues, resulted in nothing more than a "crippled hand" unable to order and coordinate at system level however simple the model. His categorical statement is that there is no exaggeration in claiming that the microfoundations project has crumbled (Hodgson, 2000, p. 108).

Really surprising, as pointed out by Soromenho (2000, pp. 7-10), it is the disproportionate amount of research dedicated to the general equilibrium (and microfoundations) in contrast with the lack of enthusiasm of the theoreticians of general equilibrium with their own programme. Everything goes as if the noted problems were minor or esoteric details. Over four decades after the works of Sonnenschein, Mantel and Debreu the textbooks containing microfoundations are still being issued, the policymakers are still using models with representative agents and the Financial Theory are still employing the efficient markets' hypothesis. In 1995, Lucas was awarded the Nobel Prize in Economic Science "for having developed and applied the hypothesis of rational expectations, and thereby having transformed macroeconomic analysis and deepened our understanding of economic policy".

It is beyond the scope of our discussion to investigate the causes of that dissonance ${ }^{10}$. Hodgson's assertion that Economics has become a field of applied mathematics is still valid. Theoretical research is almost only about the techniques

${ }^{10}$ Elster (2009) brings forward some keen and provocative hints on that. 
and the aim of shedding light on the real-world phenomena has been blurred. The economic theory has become a "mathematical game" played according to its own rules which are determined by the players and with no concern about the adequacy of the referentiality of their theories to the reality (Hodgson 2000, pp. 109-10).

It is important however to stress that the above is not a critique of mathematics in Economics per se and even less a defense of those who avoid it. In this vein, non-deterministic modeling as those developed under the umbrella of the complexity theory is promising. Such models are an alternative way of the formalizing theory, remarkable by its plasticity and its ability to incorporate specific and idiosyncratic features of the subjects to be modeled ${ }^{11}$. Still, the problem is not in mathematics but in formalism as a scientific dogma (oxymoron) and in the ontological and methodological assumptions that guide formal exercises.

\subsection{Methodologists as engineers?}

Among the recent proposals of redirecting the Economics and economic methodology we deal here with that of Colander (2013). As noted above, his complexity theory is a new and promising approach to theorizing. Colander claims that the 2007-8 economic crisis was a failure of the economics profession (and by its turn a failure of the economic methodology) as the economists were unable to persuade their colleagues about the problems of the conventional methods they employed. The author mentions DSGE models and how the economists spread it as the (only) scientific way of interpreting and intervening. Informal models based on insights about heterogeneous agents' interactions are ruled out because they violate the standard assumptions of individual rationality and systemic coordination.

Colander (2013, pp. 59-64) advances an alternative for economic methodologists: emulating engineering, practical and problem-oriented methodologies rather than occupying themselves with too abstract or too philosophical issues. Methodologists like engineers should be problem solvers using rules of thumb and practical common-sense no matter how imprecise the solutions might be. Methods should be precise only if precision is required and easily achievable. The mainstream economists, on the contrary, lay the utmost emphasis on issues of science and modeling rather than on solutions to the real-world problems. Colander's proposal implies that methodology would be also a field of applied economics and its subject matter would be to investigate specific heuristics for any problem in economics applicable to problems in other economic pursuits. Economic methodology would be much less about abstract questions. The

${ }^{11}$ For a highly positive evaluation see Squazzoni (2010) on agent-based modelling (ABM). 
methodologists, then, would play the role of chief engineers helping other engineers to do their practical work.

We are in partial accord to Colander. On one hand, his proposal embraces the perspective of promoting more humble and sensitive works on problems of a lower level of abstraction. Also, it has the merit of stressing the pragmatic character of the Economics, that of serving social aims external to the community of economists. On the other hand, his proposal is indifferent to the problem of formalism. A turn in the mainstream Economics requires a serious consideration (and Colander's proposal apparently does not include it) of the ontology of economic subjects - in the sense of discerning methods suitable to subjects to be investigated or liable to intervention. Regarding that question as "too abstract" or unnecessary is tantamount to investigating just the empirical stratum of the phenomena without saying anything about the causes as "natural necessities" of the phenomena, sliding us back to instrumentalism (Runde, 1998). In other words, Colander's proposal does not avoid the danger of producing a bunch of formal models more sophisticated and superior to those of the mainstream but, even so, insufficient to enlighten the social reality.

The range of proposals for redressing Economics must be broader also including non-formal analysis. There is no rationale for insisting on giving place of honor to formal modelling. Why must theorizing be done just this way? What can be the issue of ordinary language approaches? Why ruling out research that simply apply descriptive statistics and case studies? According to a well-known critical realist, aphorism methods should be suitable to the investigated subject not the opposite ${ }^{12}$.

\subsection{Institutions as units of analysis}

Theories that take institutions as units of analysis (Hodgson, 1993) can be a proper way of eschewing reductionism since they adopt a holistic and systemic approach. They do have several advantages: (i) institutions provide (relatively) more stable regularities of the social reality; (ii) they also provide a bridge (nondeterministic by virtue of the open nature of the individual decision) between agents' actions and systemic results; (iii) they are not static constructs as they represent the accumulated result of past actions including modifications caused by actions of current generation; and (iv) they neither place micro above macro nor vice versa.

According to Hodgson, institutions are categories or principles relatively invariant in which analysis can be done. In old institutionalism championed by

\footnotetext{
${ }^{12}$ An argument for a broader pluralism along these lines is given by Vercelli (2016, pp. 160-164).
} 
Hodgson institutions are a much broader concept ranging from technical conventions to consumption patterns (Cerqueira, 2002, p. 73). They are defined as relatively durable behavioral patterns and habits of thought or routine. On one hand, these institutions are characterized as said by relatively durable behavior patterns and habits of thought shaping how people interact within groups. On the other, the generation and selection of institutional variety explains changes in the social domain. Hence, this vision is interactive with macro level emerging from the micro one without reducing or conflating one to the other.

The conception of social reality is, thus, very different. The economic system is conceived as evolving open and, for this reason, permanently out of equilibrium. Theorizing gives painstaking attention to the environment where firms and organizations operate stressing that systemic features are capable of impinging on the behaviors of micro entities that compose the social reality. Note that taking institutions as units of analysis does not imply that individual behavior should be assumed as passive to institutional forces but mutually constitutive of that reality (Chick, 2016, pp. 100-101). The institutional approach is therefore closer in accordance with the principles of irreducibility and emergence than any sort of reductionism. As Hodgson says (2000, p. 119), "[f]ortunately, there are sophisticated alternative approaches in philosophy and social theory that emphasize the structured interaction of parts with wholes and eschew single-level explanations".

\section{Final remarks}

Colander et al. (2004) have suggested that the current heterodox critique of the mainstream are nearly forty years old and, for this reason, they miss the point. The authors say it is not possible to characterize the mainstream by the trinity of "rationality, self-interest and equilibrium" anymore. According to them, Economics is more eclectic advancing new hypotheses based on new computational and mathematical developments. Such a new approach would allow a better analysis of a complex economic reality. However, our argument is that the ontology of the individual (its mercantile sociability) and the attending reductionist methodology of the Modern Macroeconomics does have several implications on and a remarkable effect over the allegedly "scientific" or "rigorous" way of doing Economics, and so, over the policymaking.

One of those effects is the ever-increasing (and deemed irreversible) mathematization of the Economics. Even complexity economics which is an alternative to reductionist methodology pledges allegiance to the mathematical modeling. Robert Lucas in his critique of the neo-keynesian economics not only have 
established "one way" of doing Economics but also (maybe unwillingly) have linked it to the neoliberal ideology. Thus, when arguing for free choice amongst theories Colander et al. (2004) should not neglect that some approaches are excluded beforehand for its policy implications. They even affirm that some approaches can be rejected because their assumptions and methods are not suitable to what is currently deemed as mainstream. But that does not discourage the authors: any new approach needs first to draw the attention of some economic elite member in order to make the difference.

Moreover, mature knowledge must be differentiated from work currently being done in cutting-edge Economics. In other words, what is a well-established theoretical artifact must be differentiated from work in progress. Most of the conventional economics has been applied in several economic systems and is acting upon reality, in spite of any critique in papers, seminars or meetings. In this sense, orthodox economics is lingering heavily on current mainstream economics. Even if critiques are made by mainstream economists, Economics seems more resilient to change than one would expect.

Another effect is the crystallization of the notion that Macroeconomics must begin from "sound microfoundations". On that, even though macro is certainly emergent from micro it does not follow that there is only one (conventional) way of characterizing the behaviors and features of individual agents. It also does not imply disregarding macro level determinations on these same agents in the micro level. There are methods for studying and grasping the micro/macro interaction other than the conventional one - e.g., institutional analysis and simulation models. Nothing justifies conflating macro into micro. Besides, such a reduction is plagued with problems.

One escape from atomism is to regard a conception of social reality that allows a broader plurality of individual behaviors and individual/structure interaction where those levels affect each other. We stress that the institutional economics considers the endogenous change of economic system engendered by individual features and behaviors the interaction among individuals and also their interaction with the structure. Once again, however, one must note that the profession is resistant to change. Another effect of the microfoundations project has been its export to the study of other subjects in the Social Sciences. Not surprisingly the idea of optimization has invaded also the institutional approach. Besides, one could say that the mainstream has taken a conception originally critical of the neoclassical economics (with Veblen or Commons) and grafted it with criteria and constraints making the individual once again subdued to the system's determinations. 
As a final word, one should, thus, be cautious about micro reductionism (based either on heterogeneous or hyper-rational agents) or macro reductionism (based on passive choice under constraints) and its constraining of alternative theories. As pointed out by Keynes, putting established theories aside is hard because the opponent is not an external one but our own habitual modes of thought.

\section{References}

Boldyrev, I.; Svetlova, E. (eds.) (2016) "Enacting dismal science: new perspectives on the performativity of economics". London: Palgrave Macmillan.

Caldwell, B.J. (1991) "Clarifying popper", Journal of Economic Literature 29(1): p.133. JSTOR, www.jstor.org/stable/2727352,_Accessed 6 Apr. 2021.

Cerqueira, H.G. (2002) "A Economia Evolucionista: Um capítulo sistêmico da teoria econômica?", Análise Econômica 20(37), p. 55-79. https://doi.org/10.22456/2176-5456.10685

Chick, V. (2016) "On microfoundations and Keynes economics", Review of Political Economy28(1), p. 99-112. https://doi.org/10.1080/09538259.2016.1108130

Colander, D.J. (2010) "The economics profession, the financial crisis, and method", Journal of Economic Methodology 17(4), p. 419-427. https://doi.org/10.1080/1350178X.2010.525039

Colander, D.J. (2013) "The systemic failure of economic methodologists", Journal of Economic Methodology 20(1), p. 56-68. https://doi.org/10.1080/1350178X.2013.774848

Colander, D.J.; Holt, R. e Rosser Jr., J.B. (2004) "The changing face of mainstream economics", Review of Political Economy 16(4), p. 485-499. https://doi.org/10.1080/0953825042000256702

Colander, D. J.; Goldberg, M.; Haas, A.; Juselius, K.; Kirman, A.; Lux, T. e Sloth, B. (2009) "The financial crisis and the systemic failure of the economics profession”, Critical Review 21(2), p. 249-267. https://doi.org/10.1080/08913810902934109

Davis, J.B. (2008) "The turn in recent economics and return of orthodoxy". Cambridge Journal of Economics 32(3), p. 349-368. https://doi.org/10.1093/cje/bem048 
Denis, A. (2004) "Two rhetorical strategies of laissez-faire", Journal of Economic Methodology 11(3), p. 341-357. https://doi.org/10.1080/1350178042000252983

Elster, J. (1983) "Explaining technical change". Cambridge: Cambridge University Press.

Elster, J. (2009) "Excessive ambitions", Capitalism and Society 4(2), p. 1-30. https://doi.org/10.2202/1932-0213.1055

Fine, B. e Milonakis, D. (2009) "From economic imperialism to freakonomics: the shifiting boundaries between economics and other social sciences". London: Routledge.

Friedman, M. (1962) "Capitalism and freedom". Chicago: University of Chicago Press.

Fucidji, J.R.; Almeida, R.F.; Neris Jr., C.P. (2016) "Performatividade da ciência econômica: clarificando os termos e construindo pontes", 44․ Encontro Nacional de Economia ANPEC, Foz do Iguaçu, Available at https://www.anpec.org.br/encontro/2016/submissao/files_I/i1851ae7f9e68a1c9a1131391446e89123.pdf, Accessed 6 Apr. 2021.

Ganem, A. (1996) "Demonstrar a ordem racional do mercado: Reflexões em torno de um projeto impossivel". Brazilian Journal of Political Economy 16(2), p. 105 122. https://rep.org.br/rep/index.php/journal/article/view/1205

Gilbert, N. (2002) "Varieties of emergence", In: Sallach, D. (ed.) Social agents: ecology, exchange, and evolution. The 2002 Agent Conference. Chicago: University of Chicago e Argonne National Laboratory, p. 41-56.

Goodfriend, M. e King, R. (1997) "The new Neoclassical Synthesis and the role of monetary policy". NBER Macroeconomics Annual12, p. 231-283.

Hahn, F.H. e Negishi, T. (1962) "A theorem of non-tâtonnement stability", Econometrica 30(3), p. 463-469. https://doi.org/10.2307/1909889

Hayek, F.A. (1967) "Notes on the evolution of systems of rules of conduct", In: Hayek, F.A. Studies in Philosophy, Politics, and Economics. Chicago: University of Chicago Press, p. 66-81.

Hodgson, G.M. (1993) "Why the problem of reductionism in biology has implications for economics", World Futures 37(2-3): p. 69-90. https://doi.org/10.1080/02604027.1993.9972351 
Hodgson, G.M. (2000) "From micro to macro: the concept of emergence and the role of institutions", In: Burlamaqui, L.; Castro, A.; e Chang, H. (eds.) Institutions and the role of the State. New York: Edward Elgar, p. 103-126.

Hodgson, G.M. (2007) "Meanings of methodological individualism", Journal of Economic Methodology 14(2), p. 211-226. https://doi.org/10.1080/13501780701394094

Hoffmann, R. e Pelaez, V. (2011) "A psicologia econômica como resposta ao individualismo metodológico", Brazilian Journal of Political Economy31(2), p. 262-282. https://doi.org/10.1590/S0101-31572011000200006

Janssen, M.C.W. (1991) "The alleged necessity of microfoundations", Journal of Macroeconomics 13(4), p. 619-639. https://doi.org/10.1016/S01640704(05)80016-3

Janssen, M.C.W. (2008) "Microfoundations", In: Durlauf, S.N. e Blume, L.E. (eds.) The New Palgrave Dictionary of Economics 5, p. 600-604.

King, J.E. (2012) "The microfoundations delusion - metaphor and dogma in the history of macroeconomics". Cheltenham: Edward Elgar.

Kirman, A. (2016) "Complexity and economic policy: a paradigm shift or a change in perspective? - a review essay on David Colander and Roland Kuper's Complexity and the art of public policy", Journal of Economic Literature 54(2), p. 534-572. https://doi.org/10.1257/jel.54.2.534

Lawson, T. (1997) "Economics and reality", London: Routledge.

Lawson, T. (2014) "A conception of ontology", in: Pratten, S. (ed.) Social ontology and modern economics, London: Routledge, p. 19-52.

Lucas, R. E. (1987) "Models of business cycles". Oxford: Basil Blackwell.

Mäki, U. (2006). "On the method of isolation in economics", In Davis, J. e Davis, J.B. (eds), Recent developments in economic methodology, Edward Edgar, Cheltenham 3, p. 3-37.

Mayr, E. (1985) "How biology differs from the physical sciences", In: Depew, D.J. e Weber, B.H. (eds.), Evolution at a crossroads: the new biology and the new philosophy of science. Cambridge, MA: The MIT Press, p. 43-63.

O'Neill, J. (2004) "Ecological economics and the politics of knowledge: the debate between Hayek and Neurath", Cambridge Journal of Economics 28(3), p. 431447. https://doi.org/10.1093/cje/28.3.431 
Palley, T. (2013) "Gattopardo economics: the crisis and the mainstream response of change that keeps things the same", European Journal of Economics and Economic Policies Intervention 10(2), p. 193-206. https://doi.org/10.4337/ejeep.2013.02.04

Prado, E. (2006) "Microeconomia reducionista e microeconomia sistêmica", Nova Economia 16(2), p. 303-322. http://dx.doi.org/10.1590/S010363512006000200004

Rizvi, S.A.T. (1994) "The microfoundations project in general equilibrium theory", Cambridge Journal of Economics 18(4), p. 357-377. https://doi.org/10.1093/oxfordjournals.cje.a035280

Rosser Jr., J.B. (ed.) (2004) "Complexity in economics". New York: Edward Elgar.

Runde, J. (1998) "Assessing causal economic explanation", Oxford Economic Papers 50(1), p. 151-172. https://doi.org/10.1093/oxfordjournals.oep.a028639

Sawyer, R.K. (2001) "Emergence in sociology: contemporary philosophy of mind and some implications for social theory", American Journal of Sociology 107(3), p. 551-585. https://doi.org/10.1086/338780

Schaffner, K.F. (1967) "Approaches to reduction", Philosophy of Science 34(2): p. 137-147. JSTOR, www.jstor.org/stable/186101, Accessed 6 Apr. 2021.

Soromenho, J. (2000) "Microfundamentos e sociabilidade". EconomiA (Anpec) 1(2), p. $185-219$.

Squazzoni, F. (2010) "The impact of agent-based models in the social sciences after 15 years of incursions", History of Economic Ideas 18(2): p. 197-233. STOR, www.jstor.org/stable/23723517, Accessed 6 Apr. 2021.

Udéhn, L. (2001) "Methodological individualism: background, history and meaning". London: Routledge.

Udéhn, L. (2002) "The changing face of methodological individualism", Annual $\begin{array}{lllll}\text { Review of Sociology 28, p. } & \text { 479-507. }\end{array}$ https://doi.org/10.1146/annurev.soc.28.110601.140938

Vercelli, A. (2016) "Microfoundations, methodological individualism and alternative economic visions", Review of Political Economy 28(1), p. 153-167. https://doi.org/10.1080/09538259.2016.1108133 